\title{
Sulfone Anti-Infective Agent
}

National Cancer Institute

\section{Source}

National Cancer Institute. Sulfone Anti-Infective Agent. NCI Thesaurus. Code C849.

Any of substance containing a sulfonyl functional group attached to two carbon atoms

with antibiotic activity. T the general structural formula is $\mathrm{R}-\mathrm{S}(=\mathrm{O})(=0)-\mathrm{R}^{\prime}$. 